\title{
Avaliação das concentrações de metano gerado em um biorreator de bancada com base em parâmetros físico-químicos
}

\author{
Evaluation of methane concentrations generated in a \\ bench bioreactor based on physical and chemical parameters
}

\begin{abstract}
Natalí Acioly de Luna Ferreira', Kellianny Oliveira Aires², Márbara Vilar de Araújo Almeida ${ }^{3}$, Márcio Camargo de Melo ${ }^{4}$, Veruschka Escarião Dessoles Monteiro ${ }^{5}$
\end{abstract}

$\square$

\begin{abstract}
RESUMO
O monitoramento do metano $\left(\mathrm{CH}_{4}\right)$ gerado em biorreatores permite avaliar o desenvolvimento da biodegradação anaeróbia dos resíduos sólidos orgânicos (RSO). O objetivo deste artigo foi avaliar as interposições ocasionadas por fatores físico-químicos nas concentrações de metano gerado em um biorreator de bancada preenchido com RSO provenientes de uma escola da cidade de Campina Grande (PB), Brasil. A metodologia empregada na pesquisa consistiu na confecção e instrumentação de um biorreator de bancada de $0,03 \mathrm{~m}^{3}$ de capacidade, no qual foi realizado o monitoramento das concentrações de metano, análise microbiológica e dos parâmetros físico-químicos durante um período de 355 dias. A partir da análise dos resultados, foi constatado que o pH esteve acima de 7,0 durante a maior parte do monitoramento, indicando que a alcalinidade apresentada pelo material utilizado no preenchimento do biorreator foi suficiente para impedir que o acúmulo de ácidos voláteis ocorrido na fase inicial do monitoramento acarretasse a desestabilização do sistema. Dessa forma, foi possível concluir que os parâmetros físico-químicos analisados contribuíram de forma satisfatória para a biodegradação dos resíduos, levando em consideração que as concentrações de metano atingiram os níveis esperados para esse tipo de reator, chegando a valores próximos a 60\%.
\end{abstract}

Palavras-chave: biodegradação; biorreator; metano; resíduos sólidos orgânicos.

\begin{abstract}
The monitoring of the methane $\left(\mathrm{CH}_{4}\right)$ generated in bioreactors allows to evaluate the development of the anaerobic biodegradation of organic solid waste (OSW). The aim of this paper was to evaluate the interpositions caused by physicochemical factors in the methane concentrations generated on a bench bioreactor filled with OSW from a school in the city of Campina Grande (PB), Brasil. The methodology used in the research consisted in confection and instrumentation of a bioreactor of $0.03 \mathrm{~m}^{3}$ capacity, in which were carried out monitoring of methane concentrations, microbiological analysis and of the physical-chemical parameters during a period of 355 days. From the analysis of the results, was found that the $\mathrm{pH}$ was above 7.0, during for the most part of the monitoring, indicating that the alkalinity presented by the material used to fill the bioreactor was enough to impede the accumulation of volatile acids occurred in the initial phase of monitoring entailed the destabilization of the system. Thus, it was possible to concluded that the physical-chemical parameters analyzed contributed of satisfactory form for the biodegradation of the waste, leading in consideration that methane concentrations reached the levels expected for this type of reactor, reaching values close to $60 \%$.
\end{abstract}

Keywords: biodegradation; bioreactor; methane; organic solid waste.

\section{INTRODUÇÃO}

A biodegradação anaeróbia é eficaz para a redução da matéria orgânica e produção simultânea de energia. É aplicada para o tratamento de resíduos sólidos urbanos, orgânicos e águas de tratamentos residuais (RAMÍREZ-SÁENZ et al., 2009). O tratamento dos resíduos orgânicos, através da biodegradação anaeróbia, além de representar uma alternativa para resolução de problemas ambientais, promove o controle da poluição do solo, do ar e do sistema hídrico, sendo uma prática rentável tanto em sentido ambiental quanto econômico.

Uma das formas de compreender, estimar as concentrações e até produzir o biogás a partir da decomposição de resíduos sólidos $\square$

'Mestre pela Universidade Federal de Campina Grande (UFCG) - Campina Grande (PB), Brasil.

2Doutouranda na Universidade Estadual Paraíba (UEPB) - Campina Grande (PB), Brasil.

${ }^{3}$ Doutouranda na UFCG - Campina Grande (PB), Brasil.

${ }^{4}$ Doutor(a) na UFCG - Campina Grande (PB), Brasil.

${ }^{5}$ Doutor(a) na UFPE - Campina Grande (PB), Brasil.

Endereço para correspondência: Natalí Acioly de Luna Ferreira - Rua Cristino de Castro, 220 - Ibura - CEP: 51240-500 - Recife (PE), Brasil - E-mail: natali_acioly@hotmail.com Recebido: 06/02/15 - Aceito: 07/06/16 - Reg. ABES: 145766 
orgânicos (RSO) é através de biorreatores anaeróbios, que propiciam condições ideais para o desenvolvimento de microrganismos responsáveis pela biodegradação da matéria orgânica e produção de biogás.

O biogás é uma mistura gasosa composta principalmente de metano $\left(\mathrm{CH}_{4}\right)$ e dióxido de carbono $\left(\mathrm{CO}_{2}\right)$, bem como vapor d'água e diversos gases traço (PERSSON; JÖNSSON; WELLINGER, 2006). De todos os componentes, o de maior importância é o metano, pois ele representa a parte combustível do biogás e, portanto, seu teor influencia diretamente nos processos biológicos.

A conversão microbiológica de RSO em metano é bastante complexa, e requer uma interação cooperativa de diversas espécies microbianas (QUARESMA, 1992). O processo ocorre em diversas fases, e os acontecimentos envolvidos em cada uma delas influenciam diretamente nas concentrações de $\mathrm{CH}_{4}$ gerados. Segundo Amaral (2004), há três grupos de microrganismos importantes, com comportamentos fisiológicos distintos, que participam da digestão anaeróbia da matéria orgânica, transformando-a em metano e outros subprodutos: as bactérias fermentativas, as bactérias acetogênicas e as Archaeas metanogênicas.

Estudar os parâmetros físico-químicos isoladamente e como eles interagem entre si é uma importante ferramenta, uma vez que podem aumentar o desempenho dos biorreatores anaeróbios, e, assim, elevar as concentrações de metano presentes no biogás e também reduzir as substâncias tóxicas liberadas ao ambiente durante o processo degradativo dos resíduos.

O que muitas vezes é negligenciado em processos biológicos, especialmente em aterros sanitários, é que as concentrações dos gases podem afetar o comportamento microbiano. A concentração elevada de certos gases, como, por exemplo, o hidrogênio $\left(\mathrm{H}_{2}\right)$, faz com que haja a formação de compostos mais reduzidos do que o acetato, como os ácidos propiônico, butírico e outros, que funcionam como reservatório de elétrons. A formação de ácido propiônico é particularmente problemática para o processo anaeróbio global, pois sua conversão a ácido acético, etapa obrigatória para a sua metanização, é uma reação termodinamicamente exigente, que acaba acumulando-se no meio e influenciando negativamente as taxas de conversão do metano (NAGAI \& NISHIO, 1989). Dessa forma, estudar e compreender as concentrações de metano no interior de reatores anaeróbios, a partir de parâmetros físico-químicos, é de suma importância para se determinar o comportamento desses reatores e viabilizar processos mais eficientes.

O objetivo deste trabalho foi avaliar as interposições ocasionadas por fatores físico-químicos nas concentrações de metano gerado em um biorreator de bancada preenchido com RSO, provenientes de uma escola da cidade de Campina Grande (PB). Entre os parâmetros físico-químicos, foram analisados o $\mathrm{pH}$, a alcalinidade e a concentração de ácidos voláteis, por serem responsáveis por determinar as condições ácidas ou básicas do sistema, contribuindo para estabilidade do processo de biodegradação. Considerando a importância desses parâmetros no processo de digestão anaeróbia dos RSO, foram estabelecidas relações entre tais parâmetros, como também análises microbiológicas de bactérias aeróbias totais, que foram fundamentais para fornecer bases para as discussões dos resultados encontrados, além das medições das concentrações de metano.

\section{METODOLOGIA}

Este trabalho foi realizado na cidade de Campina Grande (PB), entre o período de dezembro de 2013 a dezembro de 2014, totalizando 355 dias de monitoramento. $\mathrm{O}$ desenvolvimento desta pesquisa se deu de acordo com as etapas descritas a seguir.

\section{Construção e instrumentação do biorreator}

Para realização da pesquisa, foi confeccionado um biorreator de bancada em formato cilíndrico, de seção transversal circular, com tubos de policloreto de polivinila (PVC) (Figura 1). Ele possui dimensões de $0,90 \mathrm{~m}$ de altura e 0,20 $\mathrm{m}$ de diâmetro interno, com volume aproximado de $0,03 \mathrm{~m}^{3}$.

$\mathrm{O}$ formato de estrutura cilíndrica rígida foi escolhido com o intuito de facilitar a distribuição dos resíduos em seu interior e suportar as pressões laterais na parede interna do biorreator. Para o bom desenvolvimento das Archaea metanogênicas, responsáveis pelo processo biodegradativo, o sistema foi isolado hermeticamente, com o uso de dois caps nas extremidades superior e inferior do biorreator. No cap superior, foi introduzido um manômetro de 3,0 kgf.cm ${ }^{-2}$, uma válvula de segurança e uma válvula para coleta do biogás, onde eram realizadas as medições in situ das concentrações dos gases gerados no interior do biorreator.

Com o objetivo de reduzir a entrada de ar durante a alimentação do biorreator, foi inserido um adaptador com flange, acoplado a um tubo de $0,04 \mathrm{~m}$ de diâmetro e altura de $0,70 \mathrm{~m}$, por onde os RSO foram adicionados. Na lateral do tubo, foi colocada uma válvula de esfera para retirada das amostras, e na parte frontal uma placa graduada de acrílico transparente, para avaliar o nível de líquidos presentes no biorreator.

\section{Preenchimento do biorreator}

Os RSO utilizados para preencher o biorreator foram coletados do refeitório da Escola Estadual de Ensino Médio Severino Cabral, na cidade de Campina Grande (PB). A seleção da referida escola para realização

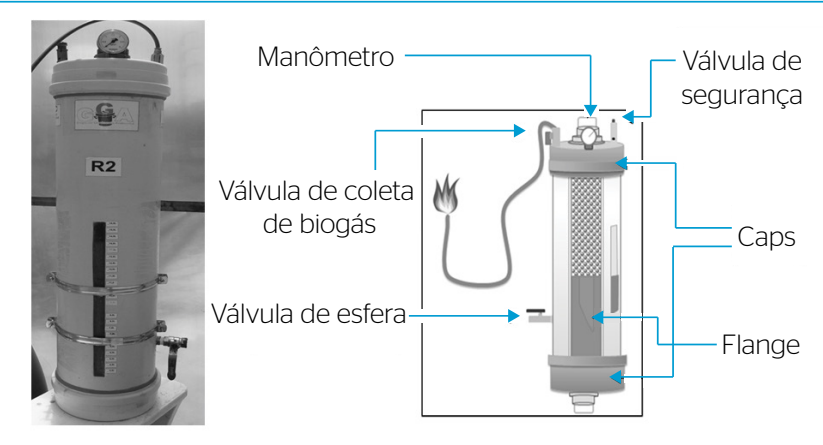

Figura 1 - Desenho esquemático do biorreator. 
desta pesquisa ocorreu por intermédio de seus integrantes, que identificaram a necessidade do desenvolvimento de projetos voltados à gestão de resíduos sólidos e procuraram o apoio da Universidade Federal de Campina Grande (UFCG).

A Escola possui cerca de 550 integrantes, entre alunos, professores, gestores e funcionários em geral; e nela foi desenvolvido um projeto de gestão de resíduos sólidos, em parceria com o Grupo de Pesquisa de Geotecnia Ambiental (GGA) e a Universidade Federal de Campina Grande (UFCG), Campus I.

Os resíduos coletados passaram por um processo de segregação para posterior trituração e preenchimento do biorreator. Antes do preenchimento, retirou-se aproximadamente, $25 \mathrm{~kg}$ da massa de RSO triturados e adicionou-se $0,014 \mathrm{~m}^{3}$ de água destilada, para estabelecer condições de umidade iniciais. Em seguida, a amostra foi submetida à adição de $3,750 \mathrm{~kg}$ de esterco bovino (inóculo), o que corresponde a $15 \%$ da massa de resíduos, considerada ideal para o melhor desempenho de biorreatores (LOPES et al. 2003). Vale ressaltar que o esterco bovino é um inóculo em potencial, uma vez que as Archaeas metanogênicas representam cerca de $40 \%$ de sua microfauna (PANDEY et al., 2011). Posteriormente, retirou-se $0,015 \mathrm{~m}^{3}$ da mistura (matéria orgânica triturada, esterco e água) que foram utilizados no preenchimento do biorreator.

No biorreator monitorado, com o objetivo de garantir valores de alcalinidade próximos aos referenciados na literatura, e de forma a manter a boa atividade das Archaeas metanogênicas, foi adicionado $0,025 \mathrm{~kg}$ bicarbonato de sódio $\left(\mathrm{NaHCO}_{3}\right)$ por quilograma de resíduo orgânico.

\section{Monitoramento dos parâmetros físico-químicos e microbiológicos dos resíduos orgânicos}

O monitoramento dos parâmetros físico-químicos e microbiológicos foi realizado quinzenalmente, a partir das amostras de resíduos coletadas no biorreator. A cada coleta, eram retirados aproximadamente $0,0003 \mathrm{~m}^{3}$ do material. As análises foram realizadas nas dependências do Laboratório de Geotecnia Ambiental da UFCG, Campus I. O Quadro 1 apresenta as metodologias utilizadas para as análises físico-químicas.

\section{Monitoramento das concentrações de metano}

As medições das concentrações de metano no interior do biorreator de bancada foram realizadas três vezes a cada semana, por meio de

Quadro 1 - Metodologia dos parâmetros usados na pesquisa.

\begin{tabular}{|c|c|c|}
\hline Parâmetros & Análise & $\begin{array}{c}\text { Método } \\
\text { Físico-Químicos }\end{array}$ \\
\hline Microbiológicos alcalinidade & $\begin{array}{c}\text { Standard Methods (APHA; } \\
\text { AWWA; WEF, 2O12); Manual de } \\
\text { e ácidos voláteis } \\
\text { análises físico-químicas de águas } \\
\text { de abastecimento e residuárias } \\
\text { (SILVA \& OLIVEIRA; 2O01) }\end{array}$ \\
\hline Aeróbios totais & $\begin{array}{c}\text { Standard Methods (APHA; } \\
\text { AWWA; WEF, } \\
\text { 2O12); Sanchez (1999) }\end{array}$ \\
\hline
\end{tabular}

um detector portátil e automático de gases com infravermelho, Dräger modelo X-am 7000. Com os dados encontrados durante essas medições, realizou-se uma média para expressar a concentração de metano referente ao período de tempo de cada quinzena, possibilitando relacionar tais concentrações com os resultados dos demais parâmetros analisados. O procedimento de leitura da concentração do biogás consiste em verificar a calibração do aparelho, aguardar o tempo de estabilização necessário (cerca de 2 minutos), conectar uma mangueira de silicone no equipamento, e, em seguida, na torneira de coleta de gás localizada no biorreator, realizar a leitura das concentrações de gases, e, por fim, desacoplar o aparelho.

\section{Análises estatísticas}

Os parâmetros foram avaliados por meio de estatística descritiva, utilizando-se o software Microsoft Excel 2007. Foi utilizado o estudo da matriz de correlação dos resultados encontrados para os parâmetros físico-químicos e as concentrações de metano. O objetivo é verificar o nível de relação entre as variáveis, destacando-se aquelas que apresentaram a existência de uma correlação mínima de $\pm 0,70$.

\section{RESULTADOS E DISCUSSÃO}

Os parâmetros físico-químicos e microbiológicos analisados neste trabalho foram utilizados na verificação do estágio de degradação da matéria orgânica, nas condições do meio interno e no comportamento do gás metano.

Os resultados obtidos nas análises do potencial hidrogeniônico $(\mathrm{pH})$ estão expressos na Figura 2.

$\mathrm{O}$ pH médio monitorado no biorreator variou entre 5,1 e 8,3 ao longo dos 355 dias de monitoramento. Esses valores estão em conformidade com Kjeldsen et al. (2002), quando afirmam que, para uma boa degradabilidade, deve-se encontrar valores de $\mathrm{pH}$ entre 4,5 a 9,0, a depender da atuação específica de cada microrganismo, e de cada fase do processo de degradação anaeróbia, já que existe uma faixa de $\mathrm{pH}$ ideal para cada uma delas.

Tais resultados são de suma importância na compreensão do processo de degradação anaeróbia dos resíduos, tendo em vista que

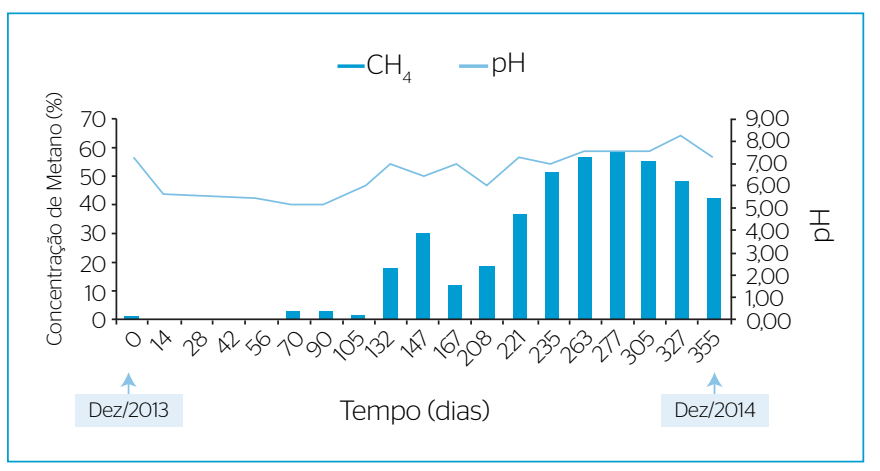

Figura 2 - Relação entre pH e a concentração volumétrica de metano. 
podem afetar a biodigestão anaeróbia e influenciar nas concentrações de metano gerado. Isso porque ele interfere diretamente na atividade enzimática dos microrganismos. O comportamento do $\mathrm{pH}$ também está relacionado aos produtos formados a partir das várias fases de degradação da matéria orgânica.

No entanto, é possível observar, na Figura 2, uma sensível queda no $\mathrm{pH}$ logo nos primeiros dias de monitoramento do biorreator, fato que é justificado devido à degradação acontecer de forma rápida, produzindo ácidos orgânicos quase que imediatamente ao início do processo, indicando a baixa capacidade de tamponamento dos materiais. Nesse período, a produção de metano foi praticamente nula. Entretanto, o $\mathrm{pH}$ a partir do $132^{\circ}$ dia de monitoramento esteve dentro da faixa considerada adequada para o desenvolvimento das Archaeas metanogênicas, criando, a partir desse período, condições favoráveis para a produção do metano. Logo após, a produção de metano foi crescente à medida que o $\mathrm{pH}$ se aproximava da neutralidade. Esse dado está em consonância com Riuji (2009), que afirma que o crescimento ótimo das Archaeas metanogênicas ocorre em faixa relativamente estreita do $\mathrm{pH}$ (em torno de 6,5 a 7,5), embora possam conseguir a estabilidade para a formação de metano numa faixa mais ampla de $\mathrm{pH}$ - entre 6 e 8.

$\mathrm{O}$ pH e a alcalinidade estão interligados; porém, não são sinônimos. A alcalinidade no monitoramento de reatores anaeróbios deve-se à necessidade do sistema em manter o $\mathrm{pH}$ dentro da faixa requerida pela população metanogênica, uma vez que a digestão de substratos complexos resulta na produção de ácidos orgânicos que precisam ser tamponados (VEEKEN et al., 2000). Dessa forma, o objetivo da alcalinidade é restringir variações bruscas do $\mathrm{pH}$, graças à capacidade que esse parâmetro apresenta de se manifestar de forma direta sobre a atividade enzimática ou, ainda, afetar indiretamente a toxicidade do meio (RIBEIRO, 2012). A alcalinidade possibilita ainda que seja determinada a tolerância em ácidos graxos voláteis, para que o valor do $\mathrm{pH}$ se mantenha na faixa pretendida. Os resultados referentes às análises de alcalinidade estão expressos na Figura 3.

De acordo com Anastácio (2010), a alcalinidade entre 2.500 e $5.000 \mathrm{mgCaCO} \cdot \mathrm{L}^{-1}$ é suficiente para se obter um adequado poder

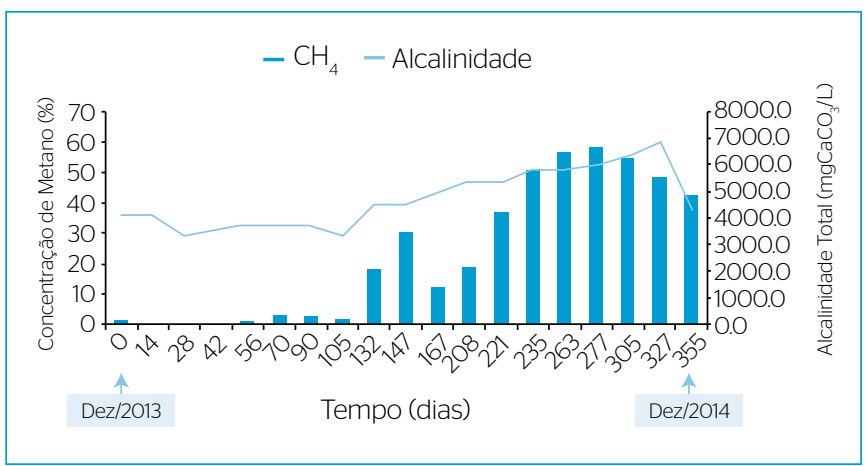

Figura 3 - Relação entre a alcalinidade e as concentrações volumétricas de metano. de tamponamento e garantir a estabilidade do sistema. Outros autores referem-se a valores para alcalinidade em uma faixa entre $1.000 \mathrm{e}$ $1.500 \mathrm{mgCaCO}{ }_{3} \cdot \mathrm{L}^{-1}$ na maior parte do período de biodegradação como desejáveis. Entretanto, estudos sobre a degradação de resíduos sólidos urbanos (RSU) realizados por Barlaz, Schaefer e Ham (1989) mostraram que concentrações variando de 6.900 a $8.000 \mathrm{mgCaCO}_{3} \cdot \mathrm{L}^{-1}$ não afetaram o sistema anaeróbio, portanto, não acarretando prejuízos ao desenvolvimento da fase metanogênica.

Vários produtos químicos podem ser usados para garantir valores adequados de alcalinidade nos sistemas anaeróbios, principalmente na fase acidogênica da degradação, na qual pode ocorrer um acúmulo de ácidos, tais como cal hidratada, cal virgem, carbonato de sódio, bicarbonato de sódio, hidróxido de sódio e bicarbonato de amônia (CHERNICHARO, 2007).

Aos 132 dias de monitoramento, com a elevação dos valores de alcalinidade e $\mathrm{pH}$, as concentrações de metano foram aumentando progressivamente até chegarem a níveis considerados ideais para esse tipo de reator, ou seja, cerca de 60\% (LEITE et al., 2009).

A Figura 4 apresenta os resultados das análises referentes às concentrações de ácidos voláteis e sua relação com as concentrações de metano, no biorreator de bancada, em função do tempo.

Os resultados obtidos para os ácidos voláteis variaram de 9.798 a $1.083 \mathrm{mgH}_{\mathrm{AC}} \cdot \mathrm{L}^{-1}$ durante os dias de monitoramento. As análises que antecederam os 90 dias de monitoramento indicaram elevada concentração de ácidos voláteis, provavelmente, em função da fase degradativa que se encontravam os resíduos. Inicialmente, durante a fase acidogênica, os compostos orgânicos complexos são convertidos em compostos mais simples, por meio da hidrólise. Em seguida, os compostos metabolizados nessa fase são convertidos em ácidos voláteis, alcoóis, ácido láctico, amônia entre outros compostos que conferem diminuição do pH. Com isso, há um aumento na concentração de ácidos (CHERNICHARO, 2007).

Após esse período, os valores referentes aos ácidos voláteis não ultrapassaram $2.000 \mathrm{mgH}_{\mathrm{AC}} \cdot \mathrm{L}^{-1}$. Em conformidade com Kroeker (1979), valores acima desse podem ser tóxicos para as Archaeas metanogênicas,

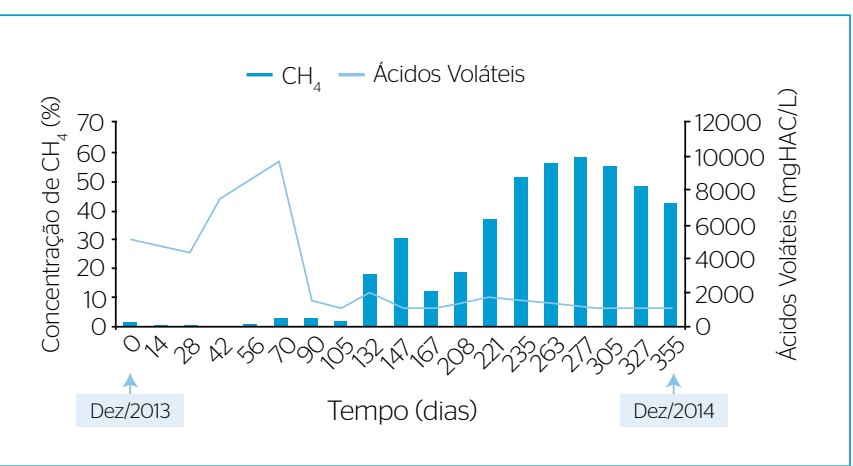

Figura 4 - Relação entre os ácidos voláteis e as concentrações volumétricas de metano. 
uma vez que podem alterar o $\mathrm{pH}$ do sistema, acidificando o meio e comprometendo a metanização do sistema.

No entanto, é possível notar uma grande amplitude no que se refere aos resultados dos ácidos voláteis citados na literatura. Kjeldsen e Christensen (1990) observaram o efeito inibitório à atividade bacteriana causado pelas concentrações de ácido acético, propiônico e butírico em concentrações acima de $6.000 \mathrm{mg}$. $\mathrm{L}^{-1}$. Porém, Leite et al. (2009) encontraram em seus estudos com biorreatores contendo resíduos sólidos vegetais e lodo de esgoto valores de 1.920 a $10.350 \mathrm{mgH}_{\mathrm{AC}} \cdot \mathrm{L}^{-1}$ e obtiveram excelentes resultados, na bioestabilização desse material. Segundo Stafford, Hawkes e Horton (1980) e Pittmann e McCarty (2001), valores nas faixas entre 2.000 e $4.000 \mathrm{mgH}_{\mathrm{AC}} \cdot \mathrm{L}^{-1}$ são considerados ideais para o desenvolvimento das Archaeas metanogênicas. Em estudos realizados por John (2004) com resíduos sólidos compostos de matéria orgânica, restos de comidas, frutas, verduras e legumes com o uso de biorreatores, foram encontrados valores de ácidos voláteis de 9.300 a $13.200 \mathrm{mgH}_{\mathrm{AC}} \cdot \mathrm{L}^{-1}$ - valores superiores aos encontrados no presente estudo.

Contudo, apesar dos valores referentes aos ácidos voláteis se apresentarem elevados durante os primeiros 90 dias de monitoramento, não houve prejuízo com relação ao desenvolvimento da fase metanogênica e, consequentemente, à produção de metano.

Ao longo do monitoramento, ocorreu uma redução nas concentrações de ácidos voláteis, havendo uma estabilização de valores abaixo de $2.000 \mathrm{mgH}_{\mathrm{AC}} \mathrm{L}^{-1}$. A partir dos 235 dias de monitoramento, provavelmente a redução ocorreu devido ao consumo desses compostos pelas Archaeas metanogênicas, conferindo, com isso, aumento do $\mathrm{pH}$. Sendo assim, na fase inicial do processo de biodegradação, o pH é normalmente mais baixo devido à produção de ácidos voláteis pelas bactérias hidrolíticas fermentativas, e, com o avanço do processo biodegradativo dos resíduos, os valores de $\mathrm{pH}$ vão se elevando em função do consumo dos ácidos voláteis pelas Archaeas metanogênicas (POHLAND \& HARPER, 1985).

A instabilidade do processo anaeróbio pode ocorrer quando a produção de ácidos voláteis é maior que seu consumo, provocando queda do pH e inibição das atividades das Archaeas metanogênicas, já que essas são bem sensíveis a mudanças de pH (AIRES, 2013).

As análises realizadas no biorreator de bancada estudado sugerem que os altos valores de ácidos voláteis sejam produtos das bactérias hidrolíticas, acidogênicas e acetogênicas, uma vez que, no biorreator, sempre foi detectada a presença de bactérias aeróbias que são produtoras de $\mathrm{CO}_{2}$ e ácidos durante todo o período de monitoramento, como mostra a Figura 5.

É possível observar (Figura 5) que, até o $90^{\circ}$ dia de monitoramento do reator, a ordem de grandeza dos microrganismos aeróbios foi de $10^{7}$ a $10^{8}$; e isso, provavelmente, permitiu o acúmulo de ácidos voláteis. Bactérias aeróbias são produtoras de ácidos voláteis, o que gera uma diminuição do $\mathrm{pH}$ - fato verificado no reator estudado. O número de microrganismos aeróbios decresceu (após 90 dias de monitoramento), houve uma diminuição dos ácidos voláteis e aumento do $\mathrm{pH}$. Pode-se perceber uma redução na ordem de grandeza de $10^{8}$ para $10^{7}$, o que pode gerar desestabilização do meio.

A partir das análises estatísticas realizadas por meio da matriz de correlação dos resultados obtidos para o $\mathrm{pH}$, ácidos voláteis, alcalinidade e concentrações de metano, foi possível estruturar a Tabela 1 .

De acordo com a análise da Tabela 1, é possível observar a existência de correlações entre a maioria dos parâmetros analisados, ou seja, apresentam valores superiores a 0,70. Entre os resultados apresentados, é possível destacar as correlações fortes e positivas estabelecidas, entre as concentrações de metano e o tempo, o pH e a alcalinidade. A correlação negativa entre o metano e os ácidos voláteis pode ser explicada pelo fato da maior produção de metano ocorrer em uma faixa de $\mathrm{pH}$ mais elevado, o que não ocorre quando há uma elevada produção de ácidos.

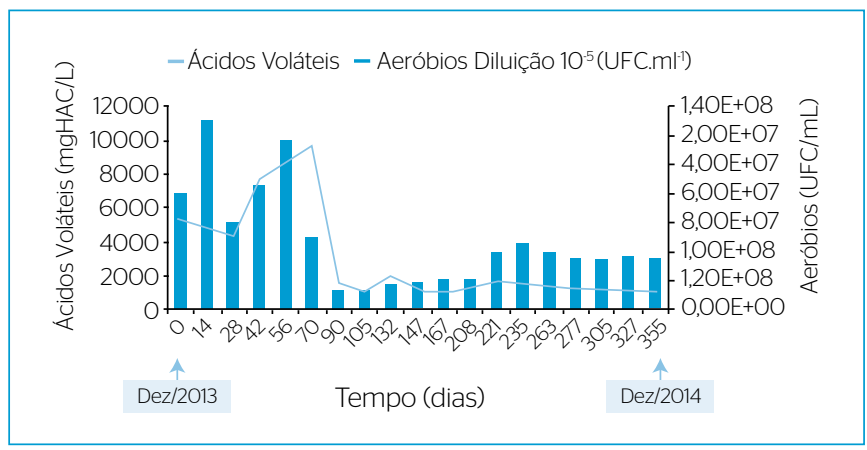

Figura 5 - Relação entre os ácidos voláteis e os aeróbios totais.

Tabela 1 - Matriz de correlação dos parâmetros analisados.

\begin{tabular}{l|c|c|c|c|c} 
& Tempo & pH & Alcalinidade & Ácidos Voláteis & \\
\hline Tempo & 1,000000000 & & & \\
\hline AH & 0,750680000 & 1,000000000 & & & \\
\hline Alcalinidade & 0,810920000 & 0,824630000 & 1,000000000 & & \\
\hline $\mathrm{CH}_{4}$ & $-0,650700000$ & $-0,567100000$ & $-0,549499523$ & 1,000000000 & \\
\hline
\end{tabular}




\section{CONCLUSÕES}

A partir dos dados obtidos, foi possível estabelecer algumas conclusões.

Os resultados encontrados para os parâmetros físico-químicos analisados contribuíram positivamente para a biodegradação dos resíduos, e para produção de metano no biorreator, uma vez que as concentrações desse gás chegaram a valores próximos a $60 \%$, o esperado para esse tipo de reator.

A fase degradativa em que se encontram os RSO presentes no biorreator estudado é a metanogênica, devido às elevadas concentrações de metano (60\%) observadas no estudo. $\mathrm{O}$ pH se manteve dentro da faixa que era esperada para cada fase do processo de degradação anaeróbia, apresentando-se mais baixo no início (fase acidogênica e acetogênica) e se elevando na fase metanogênica, o que contribuiu para as elevadas concentrações de metano gerado.

Os valores de alcalinidade apresentados foram suficientes para garantir a estabilidade do sistema durante a maior parte do processo biodegradativo dos RSO, implicando na estabilidade do $\mathrm{pH}$ na maior parte do processo. As elevadas concentrações de ácidos voláteis apresentadas no início do processo, não comprometeram a produção de metano, apresentando valores adequados ao bom desenvolvimento da biota microbiana.

O tipo de biorreator utilizado favoreceu a identificação de problemas, tais como vazamentos, infiltrações excessivas e entradas de ar que poderiam ter retardado a degradação dos resíduos orgânicos, possibilitando a realização de ajustes necessários ao experimento. Os parâmetros físico-químicos avaliados nesse estudo apresentaram uma estreita relação com as concentrações de metano, sendo indicadores importantes para avaliar o processo de digestão dos resíduos orgânicos, identificar a fase de degradação, bem como verificar a produção de metano ao longo do tempo.

\section{REFERÊNCIAS}

AIRES, K.O. (2013) Monitoramento das concentrações de gases em uma célula experimental de resíduos sólidos urbanos na cidade de Campina Grande - PB. 2013. 118 p. Dissertação (Mestrado) Universidade Federal de Campina Grande, Campina Grande.

AMARAL, F.L.M. (2004) Biodigestão anaeróbia dos resíduos sólidos urbanos: um panoroma tecnológico atual. 95 p. Dissertação (Mestrado) - Instituto de Pesquisas Tecnológicas do Estado de São Paulo, São Paulo.

ANASTÁCIO, M.C.F. (2010) Produção de energia na forma de biogás a partir de resíduos animais para o desenvolvimento rural. Dissertação (Mestrado) - Universidade do Porto, Porto.

AMERICAN PUBLIC HEALTH ASSOCIATION - APHA; AMERICAN WATER WORKS ASSOCIATION - AWWA; WATER ENVIRONMENT FEDERATION - WEF. (2012) Standard methods for the examination of water and wastewater. 21th edition. Washington: APHA. p. 1203.

BARLAZ, M.A.; SCHAEFER, D.M.; HAM, R.K. (1989) Bacterial Population development and chemical characteristics of refuse decomposition in a simulated sanitary landfill. Applied Environmental Microbiology, v. 55, p. 55-56.

CHERNICHARO, C.A.L. (2007) Princípios do tratamento biológico de águas residuárias: reatores anaeróbios. 2 ed. Belo Horizonte: DESA-UFMG, v. 5, p. 379

JOHN, C.E. (2004) Implantação de um biorreator para estudo de residuos sólidos urbanos: problemas, ajustes e soluções de laboratório. Dissertação (Mestrado) - Universidade Federal do Rio Grande do Sul, Porto Alegre.

KJELDSEN, P.; BARLAZ, M.A.; ROOKER, A.P.; BAUN, A.; LEDIN, A.; CHRISTENSEN, T.H. (2002) Present and long-term composition of MSW landfill leachate: a review. Critical Reviews in Environmental Science and Technology. v. 32, n. 4, p. 297-336.
KJELDSEN, P. \& CHRISTENSEN, T.H. (1990) Leaching tests to evaluate pollution potential of combustion residues from an iron recycling industry. Waste Management \& Research, v. 8, p. 277-292.

KROEKER, E.J.; SCHULTE, D.D.; SPARLING, A.B.; LAPP, H.M. (1979) Anaerobic treatment process stability. Journal (Water Pollution Control Federation), v. 51, n. 4, p. 178.

LEITE, V.D.; LOPES, W.S; SOUSA, J.T.; PRASAD, S.; SALOMÃO, A.S (2009) Tratamento anaeróbio de resíduos sólidos orgânicos com alta e baixa concentração de sólidos. Revista Brasileira de Engenharia Agrícola e Ambiental. v. 13, n. 2, p. 190-196.

LOPES, W.S; LEITE, V.D.; SOUZA, J.T.; PRASAD, S.; ATHAYDE JUNIOR, G.B. (2003) Fatores intervenientes no processo de tratamento anaeróbio de resíduos sólidos orgânicos. In: 22 Congresso Brasileiro de Engenharia Sanitária e Ambiental. Joinville, 2003.

NAGAI, S. \& NISHIO, N. (1989) Biological aspects of anaerobic digestion. In: CHEREMISINOFF, N.P. (Ed.) Handbook of heat and mass transfer. v. 3. Gulf Publishing, p. 701-752

PANDEY, P.; NDEGWA, P.M.; SOUPIR, M.L.; ALLDREDGE, J.R.; PITTS M.J. (2011) Efficacies of inocula on the startup of anaerobic reactors treating dairy manure under stirred and unstirred conditions Biomass and Bioenergy. v. 35, p. 2705-2720

PERSSON, M.; JÖNSSON, O.; WELLINGER, A. (2006) Biogas upgrading to vehicle fuel standards and grid injection. IEA Bioenergy, Task 37 - Energy from Biogas and Landfill Gas.

PITTMANN, B.E. \& MCCARTY, P.L. (2001) Environmental biotechnology: principles and applications. New York: McGraw-Hill. 754 p.

POHLAND, F.G. \& HARPER, S.R. (1985) Critical review and summary of leachate and gas production from landfills. Tech Project n. E2O GO1. 
QUARESMA, M.Y.V. (1992) Avaliação da eficiência e da qualidade dos resíduos gerados em biodigestores anaeróbios operados com cargas orgânicas crescentes e diferentes granulometrias de residuos sólidos domésticos. Dissertação (Mestrado) Universidade de São Paulo, São Paulo.

RAMÍREZ-SÁENZ, D.; ZARATE-SEGURA, P.B.; GUERRERO-BARAJAS, C.; GARCIA-PEÑA, E.I. (2OO9) $\mathrm{H}_{2} \mathrm{~S}$ and volatile fatty acids elimination by biofiltration: Clean-up process for biogas potential use. Journal of Hazardous Materials, v. 163, p. 1272-1281.

RIBEIRO, L.S. (2012) Estudo da degradação dos resíduos sólidos urbanos através dos parâmetros físicos e físico-químicos em um Biorreator de Escala Experimental. 2012. Dissertação (Mestrado) - Universidade Federal de Campina Grande, Campina Grande.
RIUJI, L.C. (2009) Research on anaerobic digestion of organic solid waste at household level in Dar Es Salaam, Tanzania. Tese (Bachelor) - Zurich University, Zurich.

SANCHEZ, P.S. (1999) Atualização em técnicas para o controle microbiológico de águas minerais. São Paulo: Universidade Mackenzie.

SILVA, S.A. \& OLIVEIRA, R. (2001) Manual de análises físico-químicas de águas de abastecimento e residuárias. Campina Grande, p. 270.

STAFFORD, D.A.; HAWKES, D.L.; HORTON, R. (1980) Methane production from waste organic matter. CRC Press, Inc. p. 285.

VEEKEN, A.; KALYUZHNYI, S.; SCHARFF, H.; HAMELERS, B. (2000) Effect of $\mathrm{pH}$ and VFA on hydrolisis or organic solid waste. Journal of Environmental Engineering, v. 126, n. 2, p. 1076-1081. 